\title{
The Impact of Distance Education on Learning Outcome in Computer Skills Course in Prince Sattam bin Abdulaziz University: An Experimental Study
}

\author{
Mohammed Elmetwali Mohammed Amer ${ }^{1, *}$ \\ ${ }^{1}$ Computer Science and Information Department, College of Science and Humanity Studies, Prince Sattam bin \\ Abdulaziz University, Al-Sulail, Saudi Arabia \\ *Correspondence: Computer Science and Information Department, College of Science and Humanity Studies, Prince \\ Sattam bin Abdulaziz University, Al-Sulail, Saudi Arabia. E-mail: hk_amer@yahoo.com
}

Received: August 15, 2020

Accepted: September 3, $2020 \quad$ Online Published: September 25, 2020

doi:10.5430/jct.v9n4p1

URL: https://doi.org/10.5430/jct.v9n4p1

\begin{abstract}
The present study aimed to explore the impact of distance education on the learning outcome of students in computer skills course in Prince Sattam bin Abdulaziz University in Al-Sulail, Saudi Arabia. In this study, the learning outcome is represented in the students' academic achievement. The researcher adopted an experimental approach. He selected a sample consisting from 80 male students from 4 sections of a computer skills course. Those students were divided equally into control and experimental groups. The members of the control group were taught through adopting a face-to-face instructional approach. They attended 4 face-to-face lectures. The members of the experimental group were taught online through using the Blackboard system. The researcher used a pre-test and a post-test for assessing students' academic achievement. SPSS program was used. It was found that both groups share similar levels of computer literacy. It was found that distance education has a significant positive impact on students' academic achievement in the computer skills course. The researcher recommends adding online instructional activities to the curricula used in Saudi universities.
\end{abstract}

Keywords: distance education, blackboard, academic achievement, computer skills course, Prince Sattam bin Abdulaziz University, Saudi Arabia

\section{Introduction}

Distance education may be defined as a type of education that in which the learners and instructors are spatially separated and interactive telecommunications systems are used for communication. Through using such systems, learners are provided with academic resources online (Schlosser and Simonson, 2009, p. 1). Distance education may be synchronous or asynchronous. The synchronous distance education requires the engagement of all students in the teaching-learning process in the same time. As for the asynchronous distance education, the students shall not be engaged in the teaching-learning process at the same time (Keleş and Özel, 2016).

The expression (distance education) didn't emerge recently. In fact, it emerged during the early 1700 s in America \& Great Britain. During the early 1700s, tests, course materials, assignments, notes and feedback were delivered to students through the use of postal services. During the beginning of the twentieth century, mass communication (e.g. radio and TV) were used to deliver distance education. After that, during (1980 -1990), pre-recorded videos along with cassette recordings were used to deliver distance education for learners. However, since the 1990s, internet and computers have been increasingly used for delivering distance education. Such use has been significantly increasing because computer and internet are considered very accessible and cheap (Harper et al., 2004).

Distance education can meet the educational needs of several categories of learners. For example, it can meet the educational needs of the females who aren't allowed to leave their house due to the cultural beliefs of some families and communities. In addition, it can meet the educational needs of the ones living in remote areas. Those people can receive distance without having to travel for a long distance nor pay much money for renting a house near an academic institution (Pant, 2014). 
Distance education can meet the educational needs of the students who are not capable of paying the costs of travelling to get enrolled in an academic institution. It can meet the educational needs of the ones who suffer from a disability. In this regard, it should be noted that some people with physical disabilities face difficulty in leaving their home. Thus, they can receive distance education without leaving home. Through such education, they can also take their exams and receive academic materials online (Pant, 2014).

When reviewing the relevant literature, it can be noticed that there is a debate among researchers about the effectiveness of distance education in raising students' academic achievement. For instance, some researchers - e.g. Bir (2020) - suggest that distance education negatively affects academic achievement. Other researchers - Ercana et al. (2013)- suggest otherwise. Hence, the researcher of the present study aimed to explore the impact of distance education on learning outcomes in computer skills course in Prince Sattam bin Abdulaziz University. In this study, the learning outcomes are represented in the students' academic achievement.

\section{Hypotheses}

The researcher developed the following null hypotheses:

H0.1: There isn't any statistically significant difference- at the statistical significance level of $p \leq 0.05$ - between the mean of the control group on the pre-test and the mean of the experimental group on the pre-test

H0.2: There isn't any statistically significant difference- at the statistical significance level of $p \leq 0.05$ - between the mean of the control group on the post-test and the mean of the experimental group on the post-test

\section{The Study's Question}

The present study aimed to answer the following question:

Does distance education has a statistically significant impact on students' learning outcome (i.e. academic achievement) in the computer skills course in Prince Sattam bin Abdulaziz University in Saudi Arabia?

\section{Significance of the Study}

The present study is significant due to the following reasons:

-The present study provides the officials at the Saudi Ministry of Higher education with evidence-based information. Such information enables those officials to develop effective policies for improving the quality of higher education.

-The present study provides faculty members with knowledge about the advantages of distance education.

- The present study enables the management of Prince Sattam bin Abdulaziz University to identify the effectiveness of Blackboard-distance education. That shall enable the latter management to make effective decisions in terms of investing into learning management systems.

\section{Limits of the Study}

The present study was conducted in Prince Sattam bin Abdulaziz University Al-Sulail, Saudi Arabia. It was conducting during the first semester of the academic year 2019/2020.

\section{Limitations of the Study}

The results of this study can't be generalized. That is because this study is limited to its sample and instrument. It is because all the respondents are males. It's because the results are limited to the spatial and temporal limitations of the study.

\section{Definitions}

\subsection{Theoretical Definitions}

-Learning outcomes: They may refer to the degree to which the student has learnt and understood what's required. They may refer to the degree to which the student has become able to practice the required skills. They may include students' academic achievement and satisfaction with the learning process (Ismail and Salih, 2018).

-Academic achievement refers to the degree of student's competence in doing a specific task which is measured through using tests. It is expressed in grades (Trwo, 1965). It may be defined as the amount of knowledge that the 
student's possess on a specific area or subject which is expressed through grades (Lamas, 2015).

-Distance education: It may be defined as a type of education that in which the learners and instructors are spatially separated and interactive telecommunications systems are used for communication. Through such systems, learners are provided with academic resources (Schlosser and Simonson, 2009).

\subsection{Operational Definitions}

-Learning outcome: It is represented in the academic achievement levels of the control and experimental groups after carrying out the trial. Such levels are measured through the academic achievement post-test.

-Distance education: It refers to teaching students in the computer skills course in Prince Sattam bin Abdulaziz University through using the Blackboard system. Students and instructors shall be spatially separated.

\section{Theoretical Framework}

\subsection{Learning Management Systems: Blackboard}

Learning management system refers to a web-based technology or a software application that is used for planning, carrying out and assessing the learning process. It enables instructors to assess the learning performance and outcomes of students. It enables instructors to assess students' engagement. It provides students with interactive features. Such features include: discussion forum and video conferencing. It enables instructors to provide students with access to specific resources, and assign them tasks and assignments to do. It enables students to do team work-based tasks (Alias and Zainuddin, 2005).

Learning management system has many benefits that are for the favour of the instructors and students. For instance, it enables instructors to save time, and organize the material to be illustrated during the lecture. It provides students and instructors with additional resources for expanding their knowledge. It improves the interaction between students and instructors. It provides instructors with effective methods for assessing students. It improves students' abilities in using technology. It provides students with access to the material that shall be illustrated during the lecture. (Alias and Zainuddin, 2005).

The learning management systems enable instructors to create and deliver an electronic material. They enable instructors to monitor and track students' participation and assess their performance. They enable instructors to plan, develop, implement, and assess the teaching process (Ismail and Salih, 2018). There are many learning management systems, such as the Blackboard system. The Blackboard system is a learning management system that is used by schools and universities. It is available in English, Arabic, Italian, Spanish, and French languages. It enables instructors to record lectures and send it to students. It enables students to exchange ideas. It enables students to ask questions about the way of doing the assignments. It enables students to hold discussions and interact with each other. It enables shy students to express their ideas confidently and freely. It meets the needs of various types of learners. It enables instructors to save and retrieve students' grades. It provides instructors with sample tests. It enables students to overcome the temporal and spatial barriers hindering them from learning. Thus, it serves as a flexible and convenient learning mean (Alzahrani and Aljraiwi, 2017)

The Blackboard system has many features. For instance, it enables students to have conversations and record them. It enables students to download and share files. It enables students and instructor to send messages. It enables instructors to classify learners into groups based on their needs and interests. It enables instructors to attach audio files, images, or videos to tests and materials. It enables instructors to inform students about the deadlines of assignments and presentations. (Alzahrani and Aljraiwi, 2017)

The Blackboard system enables instructors and students to save money, effort and time. It provides students with template files that enable them to adopt the required format. It promotes innovation among students and improves their thinking skills. It enables students to contact instructor from any time or place (Alzahrani and Aljraiwi, 2017)

The use of Blackboard shall increase students' satisfaction with the learning process. It shall positively affect students' achievement and improve their research skills. It increases the extent of students' engagement in the teaching-learning process. It positively affect the students' learning outcomes and learning experiences. It positively affects the students' interaction with each other. It enables students to navigate various sources of knowledge. It facilitates the process of providing students with feedback by their instructors. It provides students with opportunities to master skills. However, in order to meet the goals intended from using Blackboard, instructors must be provided with much training about the way of using the Blackboard (Ismail and Salih, 2018) 


\subsection{Distance Education}

Bradshaw and Hinton (2004) suggests that distance education have positive impacts. For instance, asynchronous online discussion can foster students' higher order thinking skills. It offers collaborative learning opportunities and improves the learning environment. It improves and facilitates students' interaction with each other. It promotes respect for the ones who have different opinions. It improves students' abilities to negotiate (Bradshaw and Hinton, 2004).

Distance education improves the quality of the provided education. That is because students shall be capable of using multimedia that may involve auditory and visual features. It enables the instructor to deliver the same lesson to a greater number of students. It enables students to share their notes with each other. That shall expand students' knowledge. It enable students to learn from each other. Distance education enables instructors to provide students with feedback. That shall enable instructors to identify the weaknesses of students and address them. It shall enables instructors to identify the gaps in the students' knowledge and the skills that students must develop (Keleş and Özel, 2016).

Distance education enables students to access the course material while they are at home without leaving their home or workplace. It spares students from using transportation which is exhausting. It facilitates and improves the interaction between the instructor and his/her students. It enables instructors to observe and analyse the students' behaviours and track students' progress (Keleş and Özel, 2016)

Web-based distance education improves students' retention. It facilitates the learning process. It reduces the time needed for learning. It provides students and instructors with many benefits. For instance, it enables students and instructors to share documents, hold video meetings, carry out online chats, and send messages. It enables students to learn at their own pace, re-access the material, and skip easily while reading. It provides young learners with fun and enjoyable learning experiences. Through web-based distance education, games can be used in the teaching-learning process (Li and Lalani, 2020)

Due to the Coronavirus, billions of dollars have been paid to invest in web-based distance education. That is because 1.2 billion children were receiving web-based education during this crisis. In fact, about 350 billion USD were invested in such education during the year 2020. In the light of such changes, online education may become an essential part of the teaching-learning process in the future. It is also believed that such changes may increase the extent of employing the blended learning model in schools and universities. However, in order to meet the intended goals from such education, teachers must prepared, trained and provided with good internet connection ( $\mathrm{Li}$ and Lalani, 2020)

\section{Previous Studies}

The researcher reviewed several empirical studies that are related to the study's subject. These studies are presented below based on the year of publication (i.e. from the oldest to the latest studies):

Abu Oqol (2012) aimed to explore the impact of employing e-learning on students' academic achievement in scientific courses in Al-Quds Open University. E-learning in this regard is represented in carrying out online learning activities. Pre-test and post-test were used. It was found employing e-learning has a significant positive impact on students' academic achievement in scientific courses in Al-Quds Open University. It was found that there is a significant difference between the academic achievement of female and male students in the post-test. The latter difference is for the favour of female. That indicates the females benefit more than males from online learning activities.

Ercana et al. (2013) aimed to explore the impact of web-based instruction on academic achievement in sensory organs subject. The sample consists from sixty $7^{\text {th }}$ grade school students. Those students are selected from Zeki Karakiz Primary School in Turkey. Pre-test and post-test were administered. It was found that there is a statistically significant difference between the students' scores on the post-test. The latter difference is for the favour of the experimental group. That means that web-based instruction plays a significant role in improving students' academic achievement

Anunobi et al. (2016) aimed to explore the impact of web-based instruction on the retention level of junior secondary school students in a computer course in Nigeria. The sample consists from 119 junior secondary school students. Pre-test and post-test were administered. A quasi-experimental approach was adopted. It was found that web-based instruction has a significant positive impact on the students' retention of technology-related concepts. 
Nyabawa (2016) aimed to explore the impact of using Blackboard on students' academic achievement in Botho University. Thirty students were interviewed and 132 students were surveyed. It was found that Blackboard positively affects students' academic achievement and learning outcomes. In addition, Blackboard can be used in all courses. It provides students with feedback quickly, improves students' communication skills, and enables students to exchange ideas. It expands students' knowledge and makes learning enjoyable. It promotes deep learning. It enables students to express their ideas confidently and increases students' engagement in the teaching-learning process. It motivates students to attend virtual classes and turn students into active learners.

Hussein (2016) aimed to explore the impact of Blackboard-based instruction on the academic achievement of pre-service teachers. He adopted an experimental approach. He used a pre-test and a post-test. The sample consists from 40 students. Those students were selected from the faculty of education at King Khalid University in Abha, Saudi Arabia. The control group consists from 20 students and the experimental group consists from 20 students. Wilcoxon Signed Ranks Test and Mann-Whitney Test were conducted to analyse data. It was found that Blackboard-based instruction has a positive significant impact on the academic achievement of pre-service teachers

Kaur (2016) aimed to explore the impact of web-based instruction on students' achievement in social studies. The sample consists from one hundred 8th grade students in Ferozepur. Pre-test and post-test were administered. It was found that there is significant difference between the academic achievement of the control and experimental groups on the post-test. This difference is for the favour of the experimental group. That indicates that web-based instruction plays a significant role in improving 8th grade students' achievement in social studies. It was found that there is a significant difference between the academic achievement of female and male students in the post-test. The latter difference is for the favour of female

Linjawi et al. (2018) aimed to explore the attitudes of university students majoring in dental education towards online learning in Saudi Arabia. They aimed to explore the readiness of those students towards receiving online learning. 100 questionnaire forms were distributed. However, 72 forms were retrieved and analysed. It was found that respondents are motivated to receive online learning. In addition, English language literacy significantly hinders students from receiving online learning. The respondents show excellent computer skills. They have e-learning experiences. They are ready to receive online learning. The poor institutional support significantly affects students' interest in receiving online learning.

Inal \& Korkmaz (2019) aimed to explore the impacts of a blended learning environment on students' academic achievement in an English language course. They aimed to explore the impact of this environment on students' attitudes towards English language courses. Forty $4^{\text {th }}$ grade students were sampled. A questionnaire was used. Pre-test and post-test were administered. It was found that students in the control and experimental groups have positive attitudes towards English language courses. It was found that of a blended learning environment on students' academic achievement. However, the blended learning environment doesn't have a significant impact on students' attitudes towards English language courses.

\section{Methodology}

\subsection{Approach}

The researcher of the present study adopts an experimental approach through using a pre-test and post-test for measuring (i.e. academic achievement).

\subsection{Procedures}

The researcher selected a sample consisting from 80 male students. Those students were selected from 4 sections of a computer skills course in Sattam bin Abdulaziz University in Al-Sulail, Saudi Arabia. The researcher contacted the instructors to inform them about the trial. He re-distributed the students in accordance with the sections during the trial in order for the control group to be similar to the experimental group in terms of size. Thus, each section consists from 20 students. The control group consists from two sections (40 students) and the experimental group consists from two sections (40 students).

The researcher chose the lessons to be taught during the trial. He developed a pre-test and a post-test for measuring students' academic achievement before and after the trial. He developed those tests in collaboration with several instructors. The pre-test was developed to make sure that both groups have similar levels of computer literacy. Having similar levels of computer literacy enables the researcher to reach accurate and valid results. The post-test aims at identifying the impact of each instructional approach on academic achievement in the computer course. Then, the researcher passed the initial version of the pre-test and the initial version of the post-test by hand to a panel of 
experts. Those experts were asked to assess the validity of those tests and make additions, deletions or adjustments to the tests. In the light of the experts' comments, the final version of each test was drafted. Then, the researcher passed the pre-test forms to both groups. He analysed the students' scores on the pre-test through SPSS. Then, the trial was initiated. To be specific, the control group was taught through using the face to face instructional approach. The experimental group was taught through using the distance education approach (i.e. pre-recorded videos). They watched the lessons on Blackboard. Each group attended 4 lectures.

These lectures cover 4 lessons in the curricula. Those lessons were also illustrated for the control group during the trial through adopting the face-to-face approach. They are identified below

a) The physical elements of the computer (input and output units, storing units, the processing unit, and memory)

b) Measurement units, motherboard parts, computer chassis and the work mechanism of the drives

c) Protection of information technologies (information security, privacy, data protection and property rights to the digital works that are registered)

d) Protection of information technologies (viruses, types, damages, reasons for prevalence, and methods of prevention) and the ethics governing the use of computer.

The latter lessons are selected form the curriculum used in the computer skills course. This curriculum is titled Introduction to computer and internet: Windows Vista, Windows 7 and Microsoft Office 2007. It was drafted by Al-Mousa (2010). After employing the two instructional methods, the post-test forms were administered to both groups through passing paper-based test forms. Then, the students' scores on the post-test forms were analysed statistically through using SPSS program. At the end, results were reached and recommendations were suggested.

\subsection{Instrument}

The researcher developed pre-test and post-test for measuring the learning outcome (i.e. academic achievement) before and after the trail. These tests include true-false questions and open ended questions. They were administered through passing paper-based test forms. The pre-test aims to measure the computer literacy. The post-test aims to measure the amount of knowledge that students about the lessons taught during the trial. Each test consists from 30 items. The maximum scores on each test are 60 scores and the minimum score is 0 .

\subsection{Validity}

The researcher measured the validity of the pre-test and post-test. That was done through passing the initial version of the pre-test and the initial version of the post-test by hand to two faculty members who are specialized in computer science. Those faculty members work in Saudi universities. They were asked to assess the tests in terms of language, clarity and relevancy. The faculty members suggested that both tests are valid, reliable and capable of meeting the study's goal. However, one of the expert recommended adding a cover page to each test to identify the goal of the trial. Thus, the final version of each test includes such a cover page.

\subsection{Reliability}

The researcher measured the reliability of the pre-test and post-test. That was done through calculating Cronbach alpha coefficient values. The Cronbach alpha coefficient value of the pre-test is 0.832 . The Cronbach alpha coefficient value of the post-test is 0.864 . Based on those values, both tests offer reliable results. That is because both of those values are greater than 0.70 as it's suggested by Salehi \& Farhang (2019).

\subsection{Methods and Criteria for Data analysis}

To analyse data, the researcher the SPSS program. He also used descriptive statistical methods (e.g. means and standard deviations). He also used inferential statistical methods (i.e. the independent t-test).

\section{Results and Discussion}

\subsection{Results and Discussion Related to the First Hypothesis}

H0.1: There isn't any statistically significant difference- at the statistical significance level of $p \leq 0.05$ - between the mean of the control group on the pre-test and the mean of the experimental group on the pre-test 
Table 1. The Results of the Independent t-test for the Scores of the Control and Experimental Groups on the Pre-Test

\begin{tabular}{lllllll}
\hline Test & Group & M & SD & Df. & T value & p-value \\
\hline \multirow{2}{*}{ pre-test } & Control & 7 & 2.3 & 36 & 0.189 & 0.163 \\
& Experimental & 8 & 1.62 & & & \\
\hline
\end{tabular}

Based on table (1), the t-value is 0.189 and the p-value is 0.163 . Thus, the first null hypothesis is accepted. That means that there isn't any statistically significant difference- at the statistical significance level of $p \leq 0.05$ - between the mean of the control group on the pre-test and the mean of the experimental group on the pre-test. The latter result indicates that both groups share similar levels of computer literacy. It indicates that Saudi universities provide much attention to the development of students' computer skills. It indicates that youth in the Saudi society have much knowledge about the use of computer programs. That may be attributed to the prevalence of technologies at Saudi homes and universities. It may be attributed to the attention provided by Saudi private and public schools to computer skills course.

\subsection{Results and Discussion Related to the Second Hypothesis}

H0.2: There isn't any statistically significant difference- at the statistical significance level of $p \leq 0.05$ - between the mean of the control group on the post-test and the mean of the experimental group on the post-test

Table 2. The Results of the Independent t-test for the Scores of the Control and Experimental Groups on the Post-Test

\begin{tabular}{lllllll}
\hline Test & Group & $\mathrm{M}$ & $\mathrm{SD}$ & $\mathrm{Df}$ & $\mathrm{T}$ value & $\mathrm{p}$-value \\
\hline Post-test & Control & 9 & 1.51 & 37 & 3.45 & 0.002 \\
& Experimental & 14.25 & 1.63 & & & \\
\hline
\end{tabular}

Based on table (2), the $t$-value is 3.45 and the p-value is 0.002 . Thus, the null hypothesis is rejected. That means that there is a statistically significant difference- at the statistical significance level of $p \leq 0.05$ - between the mean of the control group on the post-test and the mean of the experimental group on the post-test. The latter difference is for the favour of the experimental group. That indicates that distance education can significantly improve the learning outcome (i.e. academic achievement) of students in computer skills course. The latter result is consistent with the result concluded by Ercana et al. (2013). The latter researcher found that web-based instruction has a positive impact on students' on academic achievement. The latter result is consistent with the result concluded by Nyabawa (2016) and Hussein (2016). The latter researcher found that the Blackboard system has a positive significant impact on students' achievement

\section{Conclusion}

Through analysing data, it was found that both groups share similar levels of computer literacy. The latter result indicates that Saudi youth possess much information about the way of using computer programs. It was found that the Blackboard-based distance education can significantly improve the learning outcome (i.e. academic achievement) of students in computer skills course.

\section{Recommendations}

The researcher recommends:

- Providing faculty members in Saudi universities with training courses about the way of using the Blackboard system.

- Encouraging faculty members to carry online instructional activities in a regular manner.

- Adding online instructional activities to the curricula used in Saudi universities.

- Providing students at Prince Sattam bin Abdulaziz University with courses about the features of the Blackboard system

- Conducting other studies about the effectiveness of using Blackbody in other courses at Prince Sattam bin Abdulaziz University 


\section{Acknowledgement:}

The researcher would like to thank Prince Sattam bin Abdulaziz University for exerting efforts to improve the quality of education.

\section{References}

Abu Oqol, W. (2012). The impact of employing e-learning on students' academic achievement in scientific courses in Al-Quds Open University. The Palestinian Journal for Open Education, 3(6), 115-138.

Alias, N., \& Zainuddin, A. (2005). Innovation for better teaching and learning: adopting the learning management system. Malaysian Online Journal of Instructional Technology, 2(2), 27-40.

Al-Mousa, A. (2010). Introduction to computer and internet: Windows Vista, Windows 7 and Microsoft Office 2007 (6th ed.). Cairo, Egypt: UNESCO office in Cairo

Alzahrani, M. M., \& Aljraiwi, S. S. (2017). Effectiveness of Using Blackboard Collaborate tools in promoting practical skills among students of the foundation year in e-learning course. British Journal of Education, 5(4), 19-53.

Anunobi, V. N., Gambari, A. I., Abdullahi, M. B., \& Alabi, T. O. (2016). Investigating the effectiveness of web-based instruction of junior secondary school students' retention in basic technology in Nigeria. Bulgarian Journal of Science and Education Policy, 10, 273-296.

Bir, D. (2020). Comparison of academic performance of students in online VS traditional engineering course. The European Journal of Open, Distance and e-Learning, 22(1), 1-13. https://doi.org/10.2478/eurodl-2019-0001

Bradshaw, J., \& Hinton, L. (2004). Benefits of an online discussion list in a traditional distance education course. Turkish Online Journal of Distance Education-TOJDE, 5(3), 8-16. https://doi.org/10.17718/TOJDE.52165

Ercana, O., Bilen, K., \& Bulut, A. (2013). The effect of web-based instruction with educational animation content at sensory organs subject on students' academic achievement and attitudes. The fifth World Conference on Educational Sciences - (WCES). Rome, Italy, 5/7/2013- 8/7/2013.

Harper, Kimberly C., Chen, Kuanchin, \& Yen, David C. (2004). Distance learning, virtual classrooms, and teaching pedagogy in the Internet environment. Technology in Society, 26, 585-598, https://doi.org/10.1016/j.techsoc.2004.08.002

Hussein, H. (2016). The effect of Blackboard collaborate-based instruction on pre-service teachers' achievement in the EFL teaching methods course at faculties of education for girls. English Language Teaching, 9(3), 49-67. http://dx.doi.org/10.5539/elt.v9n3p49

Inal, M., \& Korkmaz, O. (2019). The effect of web based blended learning on students' academic achievement and attitudes towards English course. Education and Information Technologies, 24. https://doi.org/10.1007/s10639-019-09890-7

Ismail, A., \& Salih, A. (2018). The impact of Blackboard LMS on teaching research method course for technology studies graduate students at the Arabian Gulf University, International Journal of Information and Education Technology, 8(2), 81-94. https://doi.org/10.18178/ijiet.2018.8.2.1017

Kaur, R. (2016). Effect on web-based instructions on achievement in social studies. Journal for Humanity Science \& English Language, 4(24), 6459-6467. https://doi.org/10.21922/srjhsel.v4i24.10320

Keleş, M., \& Özel, S. (2016). A review of distance learning and learning management systems, virtual learning, Dragan Cvetkovic, IntechOpen. https://doi.org/10.5772/65222

Lamas, H. (2015). School performance, Propósitos y Representaciones, 3(1), 313-386. http://dx.doi.org/10.20511/pyr2015.v3n1.74.

Li, C., \& Lalani, F. (2020, April, 29). The COVID-19 pandemic has changed education forever. This is how. The $\begin{array}{llll}\text { World } & \text { Forum. } & \text { Retrieved } & \text { 28/7/2020 from }\end{array}$ https:/www.weforum.org/agenda/2020/04/coronavirus-education-global-covid19-online-digital-learning/

Linjawi, A., \& Alfadda, L. (2018). Students' perception, attitudes, and readiness toward online learning in dental education in Saudi Arabia: a cohort study. Advances in Medical Education and Practice, 9, 855-863, https://doi.org/10.2147/AMEP.S175395 
Nyabawa, R. (2016). Technology in learning: Blackboard usage \& its impact on academic performance: A case for universities in Lesotho. International Journal of Humanities and Management Sciences (IJHMS), 4(5), 455-461.

Pant, A. (2014). Distance learning: history, problems and solutions. Advances in Computer Science and Information Technology (ACSIT), 1(2), 65-70.

Salehi, M., \& Farhang, A. (2019). On the adequacy of the experimental approach to construct validation: the case of advertising literacy. Heliyon, 5(5). https://doi.org/10.1016/j.heliyon.2019.e01686

Schlosser, L. A., \& Simonson, M. (2009). Distance education: Definition and glossary of terms (3rd ed.). North Carolina, United States: Information Age.

Trow, W. (1956). Psychology in teaching and learning. Boston, the United States: Houghton Mifflin Company.

\section{Copyrights}

Copyright for this article is retained by the author(s), with first publication rights granted to the journal.

This is an open-access article distributed under the terms and conditions of the Creative Commons Attribution license (http://creativecommons.org/licenses/by/4.0/). 